\title{
Relationship between serum growth differentiation factor 15 , fibroblast growth factor-23 and risk of atrial fibrillation: a systematic review and meta-analysis
}

Ziqi Tan

the Second Affiliated Hospital of Nanchang University

Shanshan Huang

the Second Affiliated Hospital of Nanchang University

Menglu Liu

Seventh People's Hospital of Zhengzhou

Tiangang Song

the Second Affiliated Hospital of Nanchang University

Wengen Zhu

The First Affiliated Hospital of Sun Yat-Sen University

Jianyong $\mathrm{Ma}$

Systems Physiology University of Cincinnati College of Medicine

Jing Zhang

the Second Affiliated Hospital of Nanchang University

Peng Yu

the Second Affiliated Hospital of Nanchang University

Xiao Liu ( $\square$ liux585@mail.sys.edu.cn )

the Second Affiliated Hospital of Nanchang University

\section{Research Article}

Keywords: atrial fibrillation, growth differentiation factor 15 , fibroblast growth factor

Posted Date: February 17th, 2022

DOI: https://doi.org/10.21203/rs.3.rs-1320007/v1

License: (c) (i) This work is licensed under a Creative Commons Attribution 4.0 International License. Read Full License 


\section{Abstract}

Background and Objective: Growth differentiation factor-15 (GDF-15) and fibroblast growth factor-23 (FGF-23) were considered as predictors of the incidence of cardiovascular diseases. The present meta-analysis aimed to elucidate the associations of GDF-15 and FGF-23 with the risk of atrial fibrillation (AF).

Methods: An electronic search was conducted in Cochrane Library, PubMed, and Embase databases from inception until February 27, 2021. The study protocol was registered in PROSPERO database (CRD42020182226).

Results: In total, 15 studies that enrolled 36,017 participants were included. Both serum FGF-23 and GDF-15 was elevated in patients with AF. Analysis of categorical variables showed a higher serum FGF-23 level was associated with increased risk of AF (relative risk (RR) $=1.28,95 \%$ confidence interval (CI): 1.05 1.56), but not GDF-15 (RR=0.91, 95\% Cl: 0.20-4.04). In dose-response analysis, a linear positive association was noted between serum FGF-23 level and the risk of AF ( $\left.P_{\text {nonlinear }}=0.9507\right)$, with a RR elevation by $7 \%$ for every 20 pg/ml increase in the serum FGF-23 level (95\% Cl: 1.02-1.13). No remarkable linkage was found between serum GDF-15 level and the risk of AF, and the overall RR for the association between a $100 \mathrm{ng} / \mathrm{L}$ increment in GDF-15 level and AF was 1.01 (95\% Cl: 0.998-1.02).

Conclusion: Our study showed a positive linear correlation of serum FGF-23 level with the risk of AF. However, no significant association was found between GDF-15 and risk of AF. Further studies are warranted to clarify whether serum FGF-23 level may be significant to predict the risk of AF.

\section{Introduction}

Atrial fibrillation (AF) is the most prevalent sustained arrhythmia in clinical practice, and is associated with high morbidity and mortality [1, 2]. Although several important cardiovascular and non-cardiovascular risk factors such as hypertension, age and diabetes were identified, the prediction of AF occurrence has remained a main clinical challenge. In recent years, several biomarkers have shown a promising predictive performance for cardiovascular diseases (e.g., AF). Among them, growth/differentiation factor-15 (GDF-15) and fibroblast growth factor-23 (FGF-23) have been comprehensively investigated [3].

FGF-23 is a bone-derived hormone that plays an important role in regulating the metabolism of phosphate and 1,25-dihydroxyvitamin D [4]. In addition, it inhibits the renal synthesis of calcitriol and the secretion of parathyroid hormone from the parathyroid glands [4]. Besides, higher FGF23 levels are linked with an increased risk of cardiovascular mortality [3,5]. GDF-15 is a growth factor that belongs to the transforming growth factor- $\beta$ family. The expression of GDF15 rapidly increases in response to oxidative stress, myocardial stretch, volume overload, and myocardial inflammation [6]. The expression levels of GDF15 and FGF-23 have been shown to be associated with the prognosis of severe cardiovascular diseases, such as heart failure and AF [7, 8]. Moreover, these markers may be closely correlated with an increased risk of AF in the general population [7, 9-12]. Conversely, several cohorts have reported a null association[13]. Therefore, we aim to assess the relationship between baseline GDF-15/FGF-23 levels and the development of AF and the potential dosedependent effects.

\section{Methods}

This study was conducted following the guidelines of the Preferred Reporting Item for Systematic Review and Meta-Analysis (PRISMA) (Supplemental Table S1). Additionally, this study was registered with PROSPERO (International prospective register of systematic reviews. http: www.york.ac.uk/inst/crd)registration number- CRD42020182226.

\subsection{Literature search}

We searched the PubMed database, Embase database, and Cochrane database using the following keywords up to February 27,2021 , with no language restriction. The search terms according to PICOS were as follows:

Exposure:

For GDF-15: 'growth differentiation factor 15' OR 'macrophage inhibitory cytokine 1' OR 'prostate differentiation factor' OR 'GDF-15'.

For FGF-23: 'fibroblast growth factor-23' OR 'FGF-23 protein' OR 'fibroblast growth factor 23' OR 'FGF-23 protein' OR 'phosphatonin' OR 'tumor-derived hypophophatemia inducing factor'.

Outcomes:

For AF: 'atrial fibrillation' OR 'atrial flutter' OR 'atrial arrhythmia' OR 'atrial tachycardia'.

The detailed description of the search strategy was described in Supplemental Table S2.

\subsection{Study selection}

Endnote X9 (Thomson Reuters, New York, NY) database is used to manager all citations. The abstract that is relevant to the Association between GDF-15 and FGF-23 was reviewed for full-text.

The inclusion criteria were: (1) The article reported serum GDF-15/FGF-23 levels in the atrial fibrillation and non-atrial fibrillation populations; (2) Studies designed as observational studies (cohort, nest-control, or case-control) reported the association between baseline serum GDF-15/FGF-23 level and risk of AF, with adjusted odds ratios (OR), relative risk (RR) or hazard ratio (HR), and the corresponding $95 \%$ confidence interval (Cl), or providing data to calculate these 
estimate effects. The exclusion criteria were: (1) articles with incomplete data provided, such as letter, comment, and review; (2) the cross-sectional studies were excluded due to the high risk for bias; (3) articles involved specific genetic polymorphisms; (4) AF were expressed at tissue or cell level, such as degree of structural remodeling.

If same population were used in multiple studies, we included the most informative article.

\subsection{Data extraction and quality assessment}

According to the above inclusion criteria, the researchers (Z.Q-T and X-L) independently evaluated the eligibility of the literature. The basic characteristics of each study were extracted, including the first author, year of publication, age, gender, complications, sample size, adjusted estimated effect, $95 \%$ confidence interval of each category, and adjustments. We use the Newcastle-Ottawa Scale (NOS) for quality assessment to evaluate the quality of the articles with scores range from 0 to 9 . A higher grade $(\geq 7)$ indicates a moderate-high quality; otherwise, regarded as a low-quality $[14,15]$.

\subsection{Statistical analysis and bias risk assessment}

The researchers converted the effect measure into its natural logarithm (RR), and calculated the standard error (selog [RR]) according to the corresponding $95 \% \mathrm{Cl}$. Random-effects models were used considering the potential heterogeneity across studies. GDF-15 and FGF-23 levels were converted into a uniform unit in all included studies (pg/ml for FGF-23, ng/ml for GDF-15). To compare the GDF-15 level of between AF and control group, GDF-15 or FGF-23 level expressed as quartiles and medians are converted to mean and standard deviation $[16,17]$. We calculated the standardized mean difference (SMD) in GDF15/FGF-23 between those with AF and those without AF. The SMD represents the difference between the weighted mean and SD of the GDF-15/FGF-23 of individuals with AF and that of the controls. For the linear exposure-effect analysis, to estimate study-specific slopes and $95 \%$ Cls, the method described by Greenland and Longnecker [18] was used. The robust error meta-regression method developed by Xu and Doi[19, 20] was applied for the non-linear doseresponse analysis. It needs to know the levels of GDF-15 and FGF-23 and their estimate effect with variance estimates for at least two quantitative exposure categories. If the median or average level was not provided in the article, we used the average of the lower and upper limits of each category to estimate the midpoint. If the terminal category was open, we assumed that the length of the open interval was the same as that of the adjacent interval[21, 22]. We applied $\mathrm{I}^{2}$ statistics to estimate the heterogeneity between studies. Low heterogeneity, moderate heterogeneity, and high heterogeneity was defined as $\mathrm{I}^{2}<50 \%$, 50\%-75\%, > 75\%, respectively[23]. Review Manager (RevMan) version 5.4.1 (The Cochrane Collaboration 2014; Nordic Cochrane Center Copenhagen, Denmark) and STATA (Version 16.0, Stata Corp LP, College Station, Texas, USA) software were used for statistical analysis. P $<0.05$ with two-tails was considered statistically significant. In addition, to study possible factors influencing results, subgroup analysis stratified by study design and adjustments (sex, NT-pro BNP and CRP).

\section{Results}

\subsection{Study selection}

A total of 389 publications were initially retrieved (PubMed=78; the Cochrane Library=48; and Embase=263). After removing 50 duplicates and 188 irrelevant citations, the full-text of the remaining 151 articles were reviewed, and 15 studies (9 for GDF-15 and 6 for FGF-23) were finally included. The flowchart of the study selection is shown in Figure 1. Excluded studies with detailed reasons $(n=31)$ are summarized in Supplementary Table S3.

\subsection{Study characteristics and quality of the eligible studies}

Table 1 shows the characteristics of the eligible studies. For GDF-15, 9 studies with 1,721 cases/10,602 individuals were included. In general, the eligible studies were published from 2011 to 2020, and their sample size ranged from 100 to 3,217 participants. Four studies reported the association between serum GDF-15 level and the risk of AF in the general population [7-9, 24], 2 studies concentrated on patients who received coronary artery bypass graft [25, 26], and 2 studies reported this association in patients with recurrent AF after catheter ablation $[27,28]$. The majority of the eligible studies were performed in Europe [7, 10, 24-27] ( $n=6)$, two studies were undertaken in China [8,28], and only one study was conducted in the United States [9].

Six studies enrolling 3,138 cases and 25,415 participants reported the association between serum FGF-23 level and the risk of AF from 2014 to 2020 [3, 5, 11 , 29-31]. Four studies reported an association between FGF-23 and AF in the general population [3, 11, 29, 30], one study was based on patients with CKD [5], and one study reported an association between FGF-23 and postoperative atrial fibrillation [31]. Among them, 3 studies were performed in the United States[3, $5,11]$, and others were conducted in Asian $(n=1)$ [29] or European countries $(n=2)[30,31]$.

Ascertainment of AF in most studies was mainly conducted through electrocardiography or medical records; the study of Shao's study did not specify the measurement of AF diagnosis [8].

These studies achieved Newcastle-Ottawa Scale (NOS) scores greater than 6 points, and their estimated quality was acceptable (Supplementary Table S4).

\subsection{GDF-15}

\subsubsection{Comparison of serum GDF-15 level between patients with and without AF}

A total of 7 studies with 1200 cases/4332 individuals were included [7, 8, 24-28]. Compared with the patients with AF, serum GDF-15 level was elevated in patients with AF (standardized mean difference (SMD): $0.25,95 \% \mathrm{Cl}: 0.07-0.42 ; 12=75 \%$ ), with a significant heterogeneity (Figure $2 \mathrm{~A}$ ). 
In the categorical analysis, two cohorts (313 cases and 3153 individuals) were included $[9,26]$. The results showed that a high level of GDF-15 was not significantly associated with an increased risk of $A F(R R=0.91,95 \%$ Cl: 0.20-4.04; I2=87\%), and a significant heterogeneity was detected (Figure $2 B$ ).

In the dose-effect analysis, 5 cohorts from four publications $[9,10,24,28]$, covering 819 cases and 8281 individuals were included. The overall RR for assessing the association between a $100 \mathrm{ng} / \mathrm{L}$ increment in GDF-15 level and AF risk was 1.01 (95\% Cl: 0.998-1.02; I2=35\%), with no evidence of heterogeneity (Figure 2B). The nonlinear analysis was not performed due to limited data. In the pre-defined subgroup analyses stratified by study design, adjusted for gender, NT-pro BNP and CRP, the results were still not significant. No significant subgroup differences were found among these groups (P>0.05) (Supplementary Figures 1A-D).

\subsection{FGF-23}

\subsubsection{Comparison of FGF-23 level between patients with and without AF}

Four studies [29, 31-33] that enrolled 994 cases and 5318 individuals were included to explore the difference in FGF-23 level between AF and non-AF patients. Patients with AF exhibited an elevated serum FGF-23 level (SMD: 0.55, 95\% Cl: 0.13-0.98; I2=94\%), with substantial evidence of heterogeneity (Figure 3A).

\subsubsection{Association between FGF-23 level and risk of AF}

In the categorical analysis, three studies with 2752 cases and 23973 participants were included[3, 11, 33]. The pooled RR for the correlation of serum FGF-23 level with AF risk was 1.28 (95\% Cl: 1.05-1.56, I2=34\%), with no evidence of heterogeneity (Figure 3B). According to pre-defined subgroup analyses, the results were stable and no subgroup differences were detected among these groups $(\mathrm{P}>0.05)$ (Supplementary Figure 1E-G).

Three cohorts in two studies covering 2092 AF cases and 20,097 participants were included in the dose-response analysis [3, 11]. There was a linear correlation between serum FGF-23 level and the risk of AF ( $\left.P_{\text {non-linear }}=0.9507\right)$, with a FGF-23 cutoff value of $62 \mathrm{pg} / \mathrm{ml}$ for significantly increased risk of AF (Figure 4). The overall RR for the association between a $20 \mathrm{pg} / \mathrm{ml}$ increase in serum FGF-23 level with AF risk was 1.07 (95\% Cl: 1.02-1.13; I2=0\%), with no evidence of heterogeneity (Figure 3B). All included studies were adjusted for gender and NT-pro BNP in the exposure- response analysis; thus, the doseresponse analysis in subgroups stratified by gender and NT-pro BNP were not performed.

\section{Discussion}

\subsection{Major findings}

The present study showed that serum FGF-23 level was linearly correlated with the risk of AF, with a RR increase by $7 \%$ for every 20 pg/ml elevation in FGF-23 level. However, although AF patients had a higher serum GDF-15 level, a positive correlation of serum GDF-15 level with the risk of AF was not established, either in the categorical or continuous variables analyses.

\subsection{Comparison with previous studies}

\subsubsection{GDF-15}

The relationship between serum GDF-15 level and the risk of AF remains inconclusive [34,35]. Importantly, although we found a noticeable increase in serum GDF-15 level in patients with AF compared with those without AF, no positive correlation between GDF-15 and AF risk was found. This result was confirmed in the sensitivity and subgroup analyses. These results were not surprising. Consistently, in a community-based Swedish study, a neutral association was reported between serum GDF-15 level and the risk of $A F$ (hazard ratio (HR): 1.141, $P=0.12$ ) [36]. Notably, the GDF-15 level that can predict adverse outcomes (e.g., major bleeding) of patients with AF, rather than markers for AF incidence among the general population, has been reported. Moreover, the prognostic value of GDF-15 for other outcomes of AF patients, such as recurrence of AF after catheter ablation, was also reported in several studies [28, 37, 38]. However, owing to the limited sample size, the association between serum GDF-15 level and the risk of AF should be further evaluated.

\subsubsection{FGF-23}

As for FGF-23, previous studies regarding the association between serum FGF-23 level and the risk of AF yielded inconsistent results [3, 11, 33]. A crosssectional study of Japanese cardiac patients first reported a U-shaped relationship between serum FGF23 level and the prevalence of AF [39]. However, the ARIC study demonstrated an approximately linear correlation of serum FGF-23 level with the incidence of AF [40]. A meta-analysis indicated a positive correlation of serum FGF-23 level with the risk of AF, but only categorical variables were analyzed and the potential dose-dependent effects were not evaluated [41]. The present study, for the first time, showed a positive linear correlation of serum FGF2-3 level with the risk of AF, and a 20 pg/ml elevation in serum FGF23 level increased the risk of AF by 7\%. Notably, the relationship between serum FGF23 level and AF incidence might be markedly influenced by kidney function. Alson et al. found a linear association in the overall population in the ARIC cohort. However, a U-shaped relationship was found for a subgroup of eGFR> $60 \mathrm{~mL} / \mathrm{min}$ per $1.73 \mathrm{~m}^{2}$, and an inverse U-shaped relationship was suggested for a subgroup of eGFR $<60 \mathrm{~mL} / \mathrm{min}$ per $1.73 \mathrm{~m}{ }^{2}$ [40]. FGF-23 is a wellknown important mediator in the pathology of chronic kidney disease (CKD) [42], and these discrepancies can be justified. In the present meta-analysis, all included studies were adjusted for CKD, suggesting a CKD-independent effect assessment of the association between serum FGF-23 level and the risk of AF. Consistently, another prospective cohort study showed that, for the enrolled 3,876 patients with mild-to-severe CKD, a 1-U increase in serum FGF23 level increased the risk of AF by $47 \%$ [33]. The potential reasons for the discrepancies among these studies might be attributed to significant differences in the relevant risk factor profiles or the incidence of AF. Moreover, as an early biomarker for CKD, Klotho deficiency contributes to soft-tissue calcification in CKD, and Klotho was considered as a co-receptor for FGF23 function [43]. Besides, a-Klotho deficiency in CKD patients may exacerbate a-Klotho-independent cardiac toxicity of FGF23, thereby promoting the incidence of AF [44]. However, a limited number of studies have detected the serum a-Klotho level; therefore, 
further studies are warranted to assess the role of a-Klotho in elucidating the association between serum FGF-23 level and the risk of AF, especially in patients with CKD.

\subsection{Potential mechanisms}

Several potential mechanisms can explain the association between serum FGF-23 level and the risk of AF. FGF-23 plays a pivotal role in the regulation of mineral homeostasis, and can promote myocardial remodeling and myocardial hypertrophy, causing endothelial dysfunction [3, 45]. In case of high serum levels of FGF-23, the levels of calcium, phosphorus, and vitamin D in the body cannot be properly regulated. FGF-23 upregulation may also activate the reninangiotensin-aldosterone system (RAAS), which plays a role in atrium remodeling and influences the hemodynamics of the kidneys [46], thereby indirectly affecting the cardiac function [47]. Furthermore, studies have demonstrated that FGF-23 significantly activates the protein kinase C (PKC) signaling pathway, resulting in abnormal sodium channel conductance, affecting cardiac function and disrupting heart rate [48, 49]. In addition, FGF-23 can also activate the TGF$\beta$ signaling pathway, leading to the activation of fibroblasts [50].

\subsection{Implications and further research}

NT-proBNP and CRP play important roles in the occurrence and development of AF [13]. The association of serum FGF-23 level with the risk of AF was not noticeable in the subgroups without adjustment for NT-proBNP and CRP level in the categorical analysis, but only one study was included. Besides, in the dose-dependent effect analysis, all studies were adjusted for NT-proBNP/CRP and positive results could be achieved. The above-mentioned results suggested that FGF-23 could increase the risk of AF independent of NT-proBNP and CRP, while additional studies were needed to confirm our results.

To date, several risk models have been established for predicting the incidence of AF in the general population [34-37]. Recent studies have shed light on the roles of biomarkers in improving the predictive abilities of AF risk scores. Our study showed the predictive value of serum FGF-23 level for AF. Further studies are needed to examine the predictive performance by adding FGF-23 to the existing AF prediction scores.

Also, although our study did not yield a positive correlation between GDF-15 and AF risk, GDF-15 has been applied as a biomarker for predicting the risk of cardiovascular disease [51, 52], and prognosis of AF [53]. According to several large cohort studies, the biomarker-based ABC (age, biomarker and clinical history) scoring incorporating GDF-15 has demonstrated good predicting ability for embolization and bleeding events in AF patients [54-56]. Hijazi et al. showed that the ABC bleeding score performed better than the HAS-BLED and ORBIT scores [57], which suggests they might have a promising clinical application in the future.

\subsection{Study limitations}

This was the first study that assessed the dose-dependent associations of FGF-23 and GDF-15 with the risk of AF. Nevertheless, several limitations of this study should be pointed out. Firstly, only a relatively small number of articles was included in this meta-analysis, and some articles used unconventional units of GDF-15 level and they were excluded [36]. Secondly, a moderate or a high degree of heterogeneity was found in this meta-analysis. The heterogeneity might be partly due to differences in participants' characteristics, study design, and methods of analysis. Heterogeneity become smaller after removing Chen's study [29], which suggests the heterogeneity derives from region. Besides, race-or gender-dependent subgroup analyses were not performed because we did not have sufficient patient-level data. Thirdly, we processed midpoint imputation for the dose-dependent association assessment, which might cause bias in the results. Fourth, although serum FGF-23 level was elevated in patients with CKD, due to data restrictions, subgroup analyses stratified by CKD were not conducted. Further studies are needed to elucidate the association of serum FGF23 level with the risk of AF in patients with or without CKD. Finally, because of the inherent flaws of observational studies, causality could not be proved forcefully.

\section{Conclusions}

In summary, our study showed a positive linear correlation of serum FGF-23 level with the risk of AF. No significant association between serum GDF-15 level and the risk of AF was found. Further studies are needed to verify whether FGF-23 may be of great significance in predicting the risk of AF.

\section{Declarations}

\section{Ethics approval and consent to participate}

Not applicable.

\section{Consent for publication}

Not applicable.

\section{Funding information}

This work was supported in part by the National Natural Science Foundation of China (No. 81760050, 81760048, 82100347), the Jiangxi Provincial Natural Science Foundation for Youth Scientific Research (No. 20192ACBL21037) and China Postdoctoral Science Foundation (2021M703724).

\section{Competing interests}

The authors declare no competing financial interests. 


\section{Authors' contributions}

Guarantor of the article: X-L, P-Y

Authors' contributions: X-L contributed to the study concept and design and revised the draft. Z.Q-T and S.S-H performed the search strategy and contributed to database research, acquisition of data, and statistical analyses. All the authors participated in data analysis, reviewed, and approved the final manuscript.

\section{Availability of data and materials}

The datasets used and analyzed during the current study are available from the corresponding author on reasonable request.

\section{Acknowledgments}

We acknowledge the grant support from Guangzhou Science Technology Bureau (202102010007).

\section{References}

1. Wong, C.X., et al., Epidemiology of atrial fibrillation: the Australian and Asia-Pacific perspective. Heart, Lung and Circulation, 2017. 26(9): p. 870-879.

2. Hindricks, G., et al., 2020 ESC Guidelines for the diagnosis and management of atrial fibrillation developed in collaboration with the European Association for Cardio-Thoracic Surgery (EACTS) The Task Force for the diagnosis and management of atrial fibrillation of the European Society of Cardiology (ESC) Developed with the special contribution of the European Heart Rhythm Association (EHRA) of the ESC. European heart journal, 2021. 42(5): p. 373-498.

3. Mathew, J.S., et al., Fibroblast growth factor-23 and incident atrial fibrillation: the Multi-Ethnic Study of Atherosclerosis (MESA) and the Cardiovascular Health Study (CHS). Circulation, 2014. 130(4): p. 298-307.

4. Alonso, A., et al., Circulating fibroblast growth factor-23 and the incidence of atrial fibrillation: the Atherosclerosis Risk in Communities study. Journal of the American Heart Association, 2014. 3(5): p. e001082.

5. Mehta, R., et al., Association of fibroblast growth factor 23 With atrial fibrillation in chronic kidney disease, from the Chronic Renal Insufficiency Cohort Study. JAMA Cardiology, 2016. 1(5): p. 548-556.

6. Patel, S., et al., GDF15 Provides an Endocrine Signal of Nutritional Stress in Mice and Humans. Cell Metab, 2019. 29(3): p. 707-718.e8.

7. Santema, B.T., et al., The influence of atrial fibrillation on the levels of NT-proBNP versus GDF-15 in patients with heart failure. Clin Res Cardiol, 2020. 109(3): p. 331-338.

8. Shao, Q., et al., Circulating serum levels of growth differentiation factor-15 and neuregulin-1 in patients with paroxysmal non-valvular atrial fibrillation. Int J Cardiol, 2014. 172(2): p. e311-3.

9. Lamprea-Montealegre, J.A., et al., Cardiac Biomarkers and Risk of Atrial Fibrillation in Chronic Kidney Disease: The CRIC Study. J Am Heart Assoc, 2019. 8(15): p. e012200.

10. Rienstra, M., et al., Relation between soluble ST2, growth differentiation factor-15, and high-sensitivity troponin I and incident atrial fibrillation. Am Heart J, 2014. 167(1): p. 109-115 e2.

11. Alonso, A., et al., Circulating fibroblast growth factor-23 and the incidence of atrial fibrillation: the Atherosclerosis Risk in Communities study. J Am Heart Assoc, 2014. 3(5): p. e001082.

12. Mizia-Stec, K., et al., Lower soluble Klotho and higher impact fibroblast growth factor 23 serum levels are associated with episodes of atrial fibrillation. European Heart Journal, 2017. 38: p. 637.

13. Bening, C., et al., Atrial contractility and fibrotic biomarkers are associated with atrial fibrillation after elective coronary artery bypass grafting. Journal of Thoracic and Cardiovascular Surgery, 2020. 159(2): p. 515-523.

14. Liu, X., et al., Fluoroquinolones increase the risk of serious arrhythmias: A systematic review and meta-analysis. Medicine (Baltimore), 2017. 96(44): $\mathrm{p}$. e8273.

15. Zhu, W., et al., Association of Physical Fitness With the Risk of Atrial Fibrillation: A Systematic Review and Meta-Analysis. Clin Cardiol, 2016. 39(7): p. 4218.

16. Luo, D., et al., Optimally estimating the sample mean from the sample size, median, mid-range, and/or mid-quartile range. Stat Methods Med Res, 2018. 27(6): p. 1785-1805.

17. Wan, X., et al., Estimating the sample mean and standard deviation from the sample size, median, range and/or interquartile range. BMC Med Res Methodol, 2014. 14: p. 135. 
18. Greenland, S. and M.P. Longnecker, Methods for trend estimation from summarized dose-response data, with applications to meta-analysis. American Journal of Epidemiology, 1992. 135(11): p. 1301-9.

19. Xu, C. and D. Sar, The robust error meta-regression method for dose-response meta-analysis. International journal of evidence-based healthcare, 2017. 16(3): p. 138.

20. Xu, C., et al., Flexible piecewise linear model for investigating doseresponse relationship in meta-analysis: methodology,

examples, and comparison. PeerJ Preprints, 2018. 6:e27277v1.

21. Xu, C., et al., The methodological quality of dose-response meta-analyses needed substantial improvement: a cross-sectional survey and proposed recommendations. J Clin Epidemiol, 2019. 107: p. 1-11.

22. Liu, X., et al., The obesity paradox for outcomes in atrial fibrillation: Evidence from an exposure-effect analysis of prospective studies. Obes Rev, 2020.

21(3): p. e12970.

23. Liu, X., et al., Association of angiotensin converting enzyme inhibitors and angiotensin II receptor blockers with risk of COVID-19, inflammation level, severity, and death in patients with COVID-19: A rapid systematic review and meta-analysis. Clin Cardiol, 2020.

24. Svennberg, E., et al., NT-proBNP is a powerful predictor for incident atrial fibrillation - Validation of a multimarker approach. Int J Cardiol, 2016. 223: p. 7481.

25. Bening, C., et al., Atrial contractility and fibrotic biomarkers are associated with atrial fibrillation after elective coronary artery bypass grafting. J Thorac Cardiovasc Surg, 2020. 159(2): p. 515-523.

26. Bouchot, O., et al., Low Circulating Levels of Growth Differentiation Factor-15 Before Coronary Artery Bypass Surgery May Predict Postoperative Atrial Fibrillation. J Cardiothorac Vasc Anesth, 2015. 29(5): p. 1131-9.

27. Smit, M.D., et al., Role of inflammation in early atrial fibrillation recurrence. Europace, 2012. 14(6): p. 810-7.

28. Wei, Y., et al., The Predictive Value of Growth Differentiation Factor-15 in Recurrence of Atrial Fibrillation after Catheter Ablation. Mediators Inflamm, 2020. 2020: p. 8360936.

29. Chen, J.M., et al., Significance of serum fibroblast growth factor-23 and miR-208b in pathogenesis of atrial fibrillation and their relationship with prognosis. World J Clin Cases, 2020. 8(16): p. 3458-3464.

30. Maan, A., et al., Association between Heat Shock Protein-60 and Development of Atrial Fibrillation: Results from the Multi-Ethnic Study of Atherosclerosis (MESA). PACE - Pacing and Clinical Electrophysiology, 2016. 39(12): p. 1373-1378.

31. Mizia-Stec, K., et al., Lower soluble Klotho and higher fibroblast growth factor 23 serum levels are associated with episodes of atrial fibrillation. Cytokine, 2018. 111: p. 106-111.

32. Maan, A., et al., Association between Heat Shock Protein-60 and Development of Atrial Fibrillation: Results from the Multi-Ethnic Study of Atherosclerosis (MESA). Pacing Clin Electrophysiol, 2016. 39(12): p. 1373-1378.

33. Mehta, R., et al., Association of Fibroblast Growth Factor 23 With Atrial Fibrillation in Chronic Kidney Disease, From the Chronic Renal Insufficiency Cohort Study. JAMA Cardiol, 2016. 1(5): p. 548-56.

34. Lamprea-Montealegre, J.A., et al., Cardiac Biomarkers and Risk of Atrial Fibrillation in Chronic Kidney Disease: The CRIC Study. Journal of the American Heart Association, 2019. 8(15).

35. Wei, Y., et al., The Predictive Value of Growth Differentiation Factor-15 in Recurrence of Atrial Fibrillation after Catheter Ablation. Mediators of Inflammation, 2020. 2020.

36. Molvin, J., et al., Exploration of pathophysiological pathways for incident atrial fibrillation using a multiplex proteomic chip. Open Heart, 2020. 7(1): $\mathrm{p}$. e001190.

37. Hijazi, Z., et al., Biomarkers of inflammation and risk of cardiovascular events in anticoagulated patients with atrial fibrillation. Heart, 2016. 102(7): p. 50817.

38. Wallentin, L., et al., Growth differentiation factor 15, a marker of oxidative stress and inflammation, for risk assessment in patients with atrial fibrillation: insights from the Apixaban for Reduction in Stroke and Other Thromboembolic Events in Atrial Fibrillation (ARISTOTLE) trial. Circulation, 2014. 130(21): $\mathrm{p}$. 1847-58.

39. Miyamura, M., et al., Circulating fibroblast growth factor 23 has a U-shaped association with atrial fibrillation prevalence. Circulation Journal, 2015. 79(8): p. $1742-1748$. 
40. Alonso, A., et al., Circulating fibroblast growth factor-23 and the incidence of atrial fibrillation: the Atherosclerosis Risk in Communities study. Journal of the American Heart Association, 2014. 3(5): p. e001082.

41. Meng, L., et al., Predictive value of circulating fibroblast growth factor-23 on atrial fibrillation: A meta-analysis. Int J Cardiol, 2016. 210: p. 68-71.

42. Hannan, M., et al., Risk Factors for CKD Progression: Overview of Findings from the CRIC Study. Clin J Am Soc Nephrol, 2020.

43. Neyra, J.A., M.C. Hu, and O.W. Moe, Klotho in Clinical Nephrology: Diagnostic and Therapeutic Implications. Clin J Am Soc Nephrol, 2020. 16(1): p. 162176.

44. Hu, M.C., et al., Klotho and phosphate are modulators of pathologic uremic cardiac remodeling. J Am Soc Nephrol, 2015. 26(6): p. 1290-302.

45. Miyamura, M., et al., Circulating Fibroblast Growth Factor 23 Has a U-Shaped Association With Atrial Fibrillation Prevalence. Circ J, 2015. 79(8): p. 1742-8.

46. Stiles, M.K., et al., Paroxysmal lone atrial fibrillation is associated with an abnormal atrial substrate: characterizing the "second factor". Journal of the American College of Cardiology, 2009. 53(14): p. 1182-1191.

47. Pi, M., et al., Cardiovascular Interactions between Fibroblast Growth Factor-23 and Angiotensin II. Sci Rep, 2018. 8(1): p. 12398.

48. Si, W., et al., Fibroblast growth factor type 1 receptor stimulation of T-type Ca(2+) channels in sensory neurons requires the phosphatidylinositol 3-kinase and protein kinase A pathways, independently of Akt. Cell Signal, 2018. 45: p. 93-101.

49. Weinman, E.J., et al., Fibroblast growth factor-23-mediated inhibition of renal phosphate transport in mice requires sodium-hydrogen exchanger regulatory factor-1 (NHERF-1) and synergizes with parathyroid hormone. J Biol Chem, 2011. 286(43): p. 37216-21.

50. Nattel, S., Molecular and Cellular Mechanisms of Atrial Fibrosis in Atrial Fibrillation. JACC Clin Electrophysiol, 2017. 3(5): p. 425-435.

51. Tuegel, C., et al., GDF-15, Galectin 3, Soluble ST2, and Risk of Mortality and Cardiovascular Events in CKD. Am J Kidney Dis, 2018. 72(4): p. 519-528.

52. Wollert, K.C., T. Kempf, and L. Wallentin, Growth Differentiation Factor 15 as a Biomarker in Cardiovascular Disease. Clin Chem, 2017. 63(1): p. 140-151.

53. Nopp, S., et al., Growth differentiation factor-15 predicts major adverse cardiac events and all-cause mortality in patients with atrial fibrillation. Eur J Intern Med, 2021. 88: p. 35-42.

54. Berg, D.D., et al., Performance of the ABC scores for assessing the risk of stroke or systemic embolism and bleeding in patients with atrial fibrillation in ENGAGE AF-TIMI 48. Circulation, 2019. 139(6): p. 760-771.

55. Hijazi, Z., et al., A biomarker-based risk score to predict death in patients with atrial fibrillation: the ABC (age, biomarkers, clinical history) death risk score. Eur Heart J, 2018. 39(6): p. 477-485.

56. Pol, T., et al., Evaluation of the prognostic value of GDF-15, ABC-AF-bleeding score and ABC-AF-death score in patients with atrial fibrillation across different geographical areas. Open Heart, 2021. 8(1).

57. Hijazi, Z., et al., The novel biomarker-based ABC (age, biomarkers, clinical history)-bleeding risk score for patients with atrial fibrillation: a derivation and validation study. Lancet, 2016. 387(10035): p. 2302-2311.

\section{Tables}

Table 1. Basic characteristics of the articles included in the meta-analysis of GDF 15, FGF-23 and risk of atrial fibrillation 


\begin{tabular}{|c|c|c|c|c|c|c|c|c|}
\hline Author, years & Country & $\begin{array}{l}\text { Study design/Mean } \\
\text { follow-up time }\end{array}$ & $\begin{array}{l}\text { Study } \\
\text { populations }\end{array}$ & $\begin{array}{l}\text { Cases/Sample } \\
\text { size }\end{array}$ & $\begin{array}{l}\text { Mean } \\
\text { age/Male }\end{array}$ & $\begin{array}{l}\text { Baseline } \\
\text { comorbidities } \\
\text { (\%) }\end{array}$ & $\begin{array}{l}\text { AF } \\
\text { diagnosis }\end{array}$ & $\begin{array}{l}\text { Outcome } \\
\text { report }\end{array}$ \\
\hline \multicolumn{9}{|l|}{ GDF-15 } \\
\hline \multirow[t]{2}{*}{ Bening, 2019} & \multirow[t]{2}{*}{ Germany } & \multirow[t]{2}{*}{ Prospective cohort/NA } & NA & \multirow[t]{2}{*}{$38 / 229$} & \multirow[t]{2}{*}{$68.45 / 83.41 \%$} & \multirow[t]{2}{*}{ NA } & \multirow[t]{2}{*}{ ECG } & \multirow[t]{2}{*}{ Difference } \\
\hline & & & $\begin{array}{l}\text { Postoperative } \\
\text { atrial } \\
\text { fibrillation }\end{array}$ & & & & & \\
\hline \multirow[t]{3}{*}{$\begin{array}{l}\text { Bouchot, } \\
2015\end{array}$} & \multirow[t]{3}{*}{ France } & \multirow{3}{*}{$\begin{array}{l}\text { Prospective cohort/1 } \\
\text { year }\end{array}$} & $\begin{array}{l}\text { University } \\
\text { Hospital of }\end{array}$ & \multirow[t]{3}{*}{$34 / 100$} & \multirow[t]{3}{*}{$64.02 / 92.00 \%$} & \multirow{3}{*}{$\begin{array}{l}\text { Hypertension: } \\
64.0 \\
\\
\text { Diabetes: } \\
36.0\end{array}$} & \multirow[t]{3}{*}{ ECG } & \multirow{3}{*}{$\begin{array}{l}\text { Difference } \\
\text { Risk of AF }\end{array}$} \\
\hline & & & Dijon & & & & & \\
\hline & & & $\begin{array}{l}\text { Postoperative } \\
\text { atrial } \\
\text { fibrillation }\end{array}$ & & & & & \\
\hline \multirow[t]{3}{*}{$\begin{array}{l}\text { Lamprea- } \\
\text { Montealegre, } \\
2019\end{array}$} & \multirow[t]{3}{*}{ USA } & \multirow[t]{3}{*}{$\begin{array}{l}\text { Prospective cohort/1 } \\
\text { year }\end{array}$} & $\begin{array}{l}\text { Chronic Renal } \\
\text { Insufficiency } \\
\text { Cohort study }\end{array}$ & \multirow[t]{3}{*}{$279 / 3053$} & \multirow[t]{3}{*}{ NA/NA } & $\begin{array}{l}\text { CVD history: } \\
28.0\end{array}$ & \multirow[t]{3}{*}{ ECG } & \multirow[t]{3}{*}{ Risk of $\mathrm{AF}$} \\
\hline & & & CKD patients & & & $\begin{array}{l}\text { HF history: } \\
6.0\end{array}$ & & \\
\hline & & & & & & $\begin{array}{l}\text { Diabetes: } \\
48.0\end{array}$ & & \\
\hline \multirow[t]{3}{*}{ Rienstra,2014 } & \multirow[t]{3}{*}{ Netherlands } & \multirow[t]{3}{*}{$\begin{array}{l}\text { Retrospective } \\
\text { cohort/10 years }\end{array}$} & \multirow{3}{*}{$\begin{array}{l}\text { Community- } \\
\text { based } \\
\text { Framingham } \\
\text { Heart Study }\end{array}$} & \multirow[t]{3}{*}{$242 / 3217$} & \multirow[t]{3}{*}{$59.00 / 46.00 \%$} & $\begin{array}{l}\text { Diabetes: } \\
11.0\end{array}$ & \multirow[t]{3}{*}{ ECG } & \multirow[t]{3}{*}{ Risk of AF } \\
\hline & & & & & & HF: 1.0 & & \\
\hline & & & & & & $\begin{array}{l}\text { Myocardial } \\
\text { infarction: } \\
4.0\end{array}$ & & \\
\hline \multirow[t]{3}{*}{$\begin{array}{l}\text { Santema, } \\
2019\end{array}$} & Netherlands & Prospective cohort/NA & $\begin{array}{l}\text { Six centers in } \\
\text { Scotland }\end{array}$ & $733 / 1758$ & $72.50 / 72.53 \%$ & $\begin{array}{l}\text { Diabetes } \\
\text { history: } 34.5 \text {; }\end{array}$ & ECG & Difference \\
\hline & & & & & & $\begin{array}{l}\text { Stroke } \\
\text { history: 10.4; }\end{array}$ & & \\
\hline & & & & & & $\begin{array}{l}\text { Hypertension } \\
\text { history: } 68.9\end{array}$ & & \\
\hline Shao, 2014 & China & Prospective cohort/NA & $\begin{array}{l}\text { Second } \\
\text { Hospital of }\end{array}$ & $67 / 134$ & $66.60 / 43.38 \%$ & $\begin{array}{l}\text { Hypertension: } \\
65.7\end{array}$ & NA & \\
\hline & & & $\begin{array}{l}\text { Tianjin } \\
\text { Medical } \\
\text { University }\end{array}$ & & & $\begin{array}{l}\text { Diabetes: } \\
13.4\end{array}$ & & Risk of AF \\
\hline Smit,2011 & Netherlands & $\begin{array}{l}\text { Prospective cohort/1 } \\
\text { year }\end{array}$ & $\begin{array}{l}\text { University } \\
\text { Medical Center } \\
\text { Groningen }\end{array}$ & $30 / 100$ & $65.00 / 74.00 \%$ & $\begin{array}{l}\text { Hypertension: } \\
67.0\end{array}$ & ECG & Difference \\
\hline & & & $\mathrm{AF}$ recurrence & & & $\begin{array}{l}\text { HF history: } \\
20.0\end{array}$ & & \\
\hline & & & & & & $\begin{array}{l}\text { Coronary } \\
\text { artery } \\
\text { disease: } 18.0\end{array}$ & & \\
\hline & & & & & & $\begin{array}{l}\text { Diabetes: } \\
14.0\end{array}$ & & \\
\hline $\begin{array}{l}\text { Svennberg, } \\
2016\end{array}$ & Sweden & $\begin{array}{l}\text { Prospective cohort/13 } \\
\text { years }\end{array}$ & $\begin{array}{l}\text { The Uppsala } \\
\text { Longitudinal } \\
\text { Study of Adult } \\
\text { Men }\end{array}$ & $113 / 883$ & $71.00 / 100.00 \%$ & $\begin{array}{l}\text { Diabetes: } \\
10.3\end{array}$ & ECG & Difference \\
\hline & & $\begin{array}{l}\text { Prospective cohort/10 } \\
\text { years }\end{array}$ & $\begin{array}{l}\text { The } \\
\text { Prospective } \\
\text { Investigation }\end{array}$ & $148 / 978$ & $70.00 / 49.00 \%$ & Diabets: 11.7 & & \\
\hline
\end{tabular}




\begin{tabular}{|c|c|c|c|c|c|c|c|c|}
\hline & & & $\begin{array}{l}\text { of the } \\
\text { Vasculature in } \\
\text { Uppsala } \\
\text { Seniors }\end{array}$ & & & & & \\
\hline \multirow[t]{5}{*}{ Wei,2020 } & \multirow[t]{5}{*}{ China } & \multirow{5}{*}{$\begin{array}{l}\text { Prospective cohort/14 } \\
\text { months }\end{array}$} & \multirow{5}{*}{$\begin{array}{l}\text { Peking } \\
\text { University } \\
\text { Third Hospital } \\
\text { Postoperative } \\
\text { atrial } \\
\text { fibrillation }\end{array}$} & \multirow[t]{5}{*}{$37 / 150$} & \multirow[t]{5}{*}{$64.00 / 56.76 \%$} & Hypertension & \multirow[t]{5}{*}{ ECG } & Difference \\
\hline & & & & & & \multirow{3}{*}{$\begin{array}{l}\text { Diabetes: } \\
23.3 \\
\text { Coronary } \\
\text { artery diseas: } \\
12.7\end{array}$} & & \multirow{4}{*}{ Risk of AF } \\
\hline & & & & & & & & \\
\hline & & & & & & & & \\
\hline & & & & & & $\begin{array}{l}\text { Chronic HF: } \\
6.7\end{array}$ & & \\
\hline
\end{tabular}

\section{FGF-23}

Alonso®2014 USA

Retrospective

cohort/17 years

Atherosclerosis $1572 / 12349 \quad$ NA/NA
Risk in
Communities
study

Diabetes:

14.3

ECG

Risk of AF

study

\begin{tabular}{|c|c|c|c|c|c|c|c|c|}
\hline Chen $₫ 2020$ & China & Prospective cohort/NA & $\begin{array}{l}\text { Dongguan } \\
\text { Songshan } \\
\text { Lake Central } \\
\text { Hospital }\end{array}$ & $240 / 390$ & $60.01 / 68.21 \%$ & NA & ECG & Difference \\
\hline Maan, 2016 & Greece & $\begin{array}{l}\text { Retrospective } \\
\text { cohor/10.6 years }\end{array}$ & $\begin{array}{l}\text { Multi-Ethnic } \\
\text { Study of } \\
\text { Atherosclerosis } \\
\text { study }\end{array}$ & $77 / 983$ & $59.68 / 43.03 \%$ & $\begin{array}{l}\text { Diabetes: } \\
11.2\end{array}$ & ECG & $\begin{array}{l}\text { Difference } \\
\text { Risk of AF }\end{array}$ \\
\hline $\begin{array}{l}\text { Mathew } \square \\
2014\end{array}$ & USA & $\begin{array}{l}\text { Retrospective } \\
\text { cohor/7.7 yearst }\end{array}$ & $\begin{array}{l}\text { Multi-Ethnic } \\
\text { Study of } \\
\text { Atherosclerosis }\end{array}$ & $291 / 6398$ & NA/46.73\% & $\begin{array}{l}\text { Diabetes: } \\
12.3 \\
\text { Hypertension: } \\
36.4\end{array}$ & $\begin{array}{l}\text { ECG and } \\
\text { physician } \\
\text { claims } \\
\text { data }\end{array}$ & Risk of AF \\
\hline
\end{tabular}

$\begin{array}{lllll}\begin{array}{l}\text { Retrospective } \\ \text { cohort/8 years }\end{array} & \text { Cardiovascular } & \text { 229/1350 } & \text { NA/28.67\% } & \text { Diabetes: } \\ & \text { Health Study } & & & 10.6\end{array}$

Hypertension:

46.0

Mehta $2016 \quad$ USA Prospective cohort/7.6 years
Chronic Renal $\quad 660 / 3876$
Insufficiency Cohort

CKD patients
Hypertension: ECG 86.1

Diabetes:

48.5

HF: 9.7

CVD: 13.5

Page 10/14 


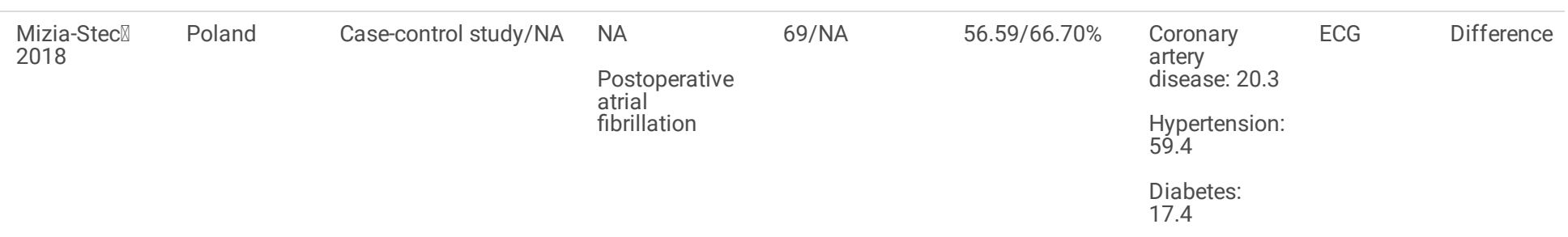

Abbreviations:

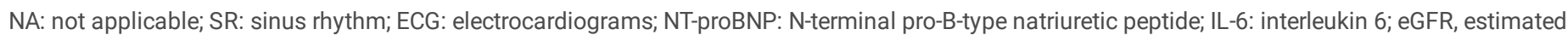

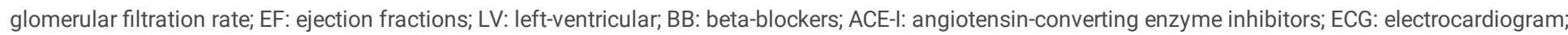

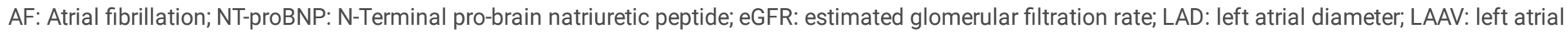

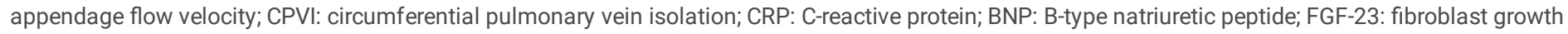

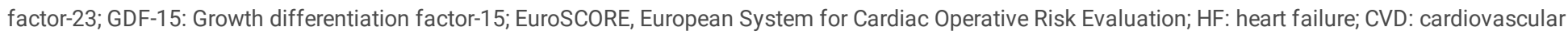
disease; CKD: chronic kidney disease. Difference: comparison of serum GDF-15 or FGF-23 level between patients with and without AF.

\section{Figures}
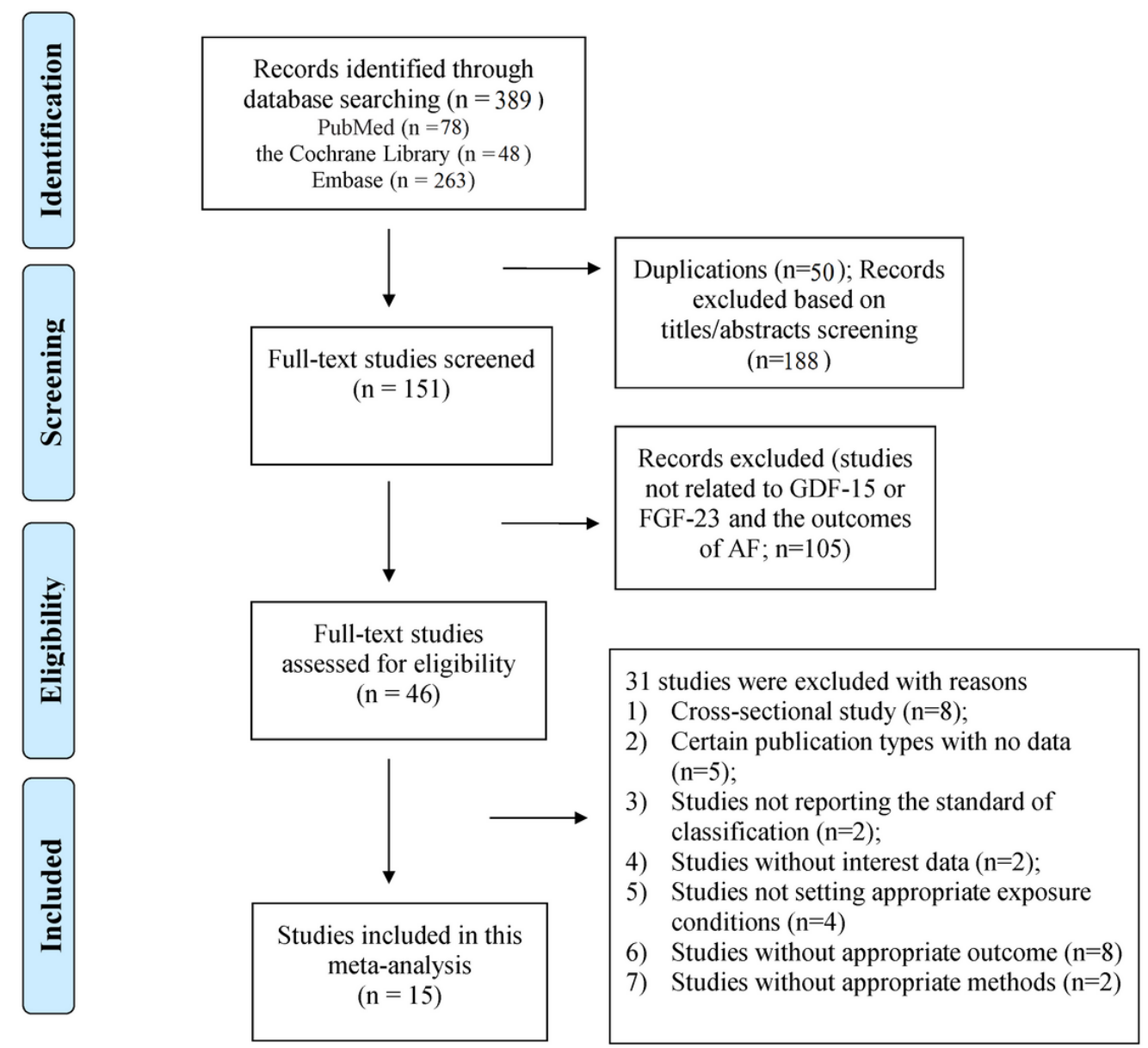

Figure 1

Flowchart of the study selection. 


\section{A. Comparison of serum GDF-15 level between patients with and without AF}

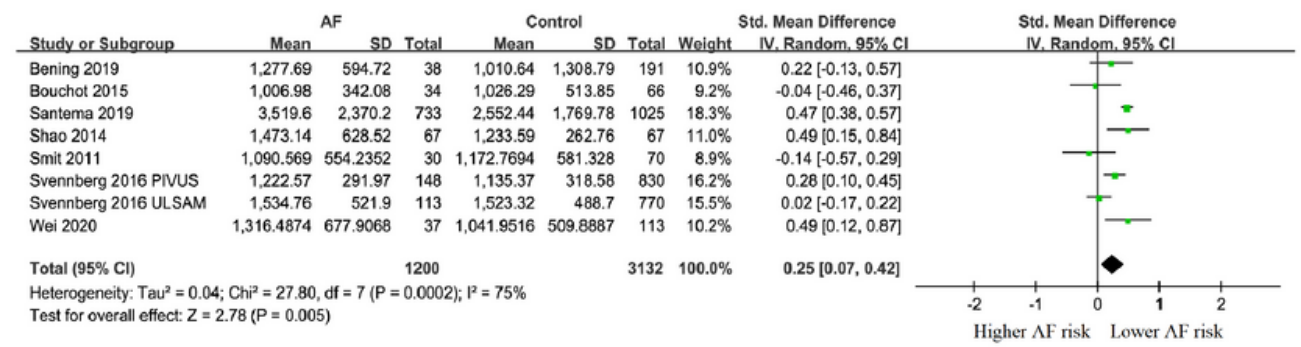

\section{B. Association between GDF-15 and risk of AF}

Highest vs lowest

\begin{tabular}{|c|c|c|c|c|c|c|c|c|}
\hline Study or Subgroup & log[Risk Ratio] & SE & Weight & $\begin{array}{l}\text { Risk Ratio } \\
\text { IV. Random. } 95 \% \mathrm{Cl}\end{array}$ & & $\begin{aligned} & \text { Risk } \text { P } \\
& \text { IV. Rando }\end{aligned}$ & $\begin{array}{l}\text { Ratio } \\
\text { om. } 95 \% \mathrm{Cl}\end{array}$ & \\
\hline Bouchot 2015 & -0.8916 & 0.4492 & $47.7 \%$ & $0.41[0.17,0.99]$ & & & & \\
\hline Lamprea-Montealegre 2019 & 0.6313 & 0.312 & $52.3 \%$ & $1.88[1.02,3.47]$ & & & & \\
\hline Total $(95 \% \mathrm{Cl})$ & & & $100.0 \%$ & $0.91[0.20,4.04]$ & & & & \\
\hline \multicolumn{4}{|c|}{$\begin{array}{l}\text { Heterogeneity: } \text { Tau }^{2}=1.01 ; \mathrm{Chi}^{2}=7.75, \mathrm{df}=1(\mathrm{P}=0.005) ; \mathrm{I}^{2}=87 \% \\
\text { Test for overall effect: } Z=0.13(P=0.90)\end{array}$} & & 0.005 & 0.1 & 10 & 200 \\
\hline
\end{tabular}

\section{Dose-response analysis, per $100 \mathrm{ng} / \mathrm{ml}$ increase}

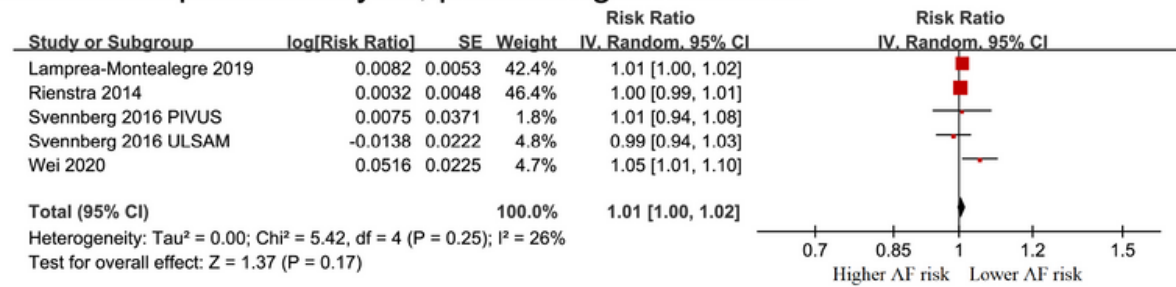

\section{Figure 2}

Forest plot showing the differences in serum growth differentiation factor 15 in control without AF and patients with AF (A) and the association between serum growth differentiation factor 15 and atrial fibrillation (B), upper panel: categorical analysis between growth differentiation factor 15 level and the risk of AF; lower panel: dose-response association between growth differentiation factor 15 and the risk of atrial fibrillation, per a $100 \mathrm{ng} / \mathrm{ml}$ increase. 


\section{A. Comparison of FGF-23 level between patients with and without AF}

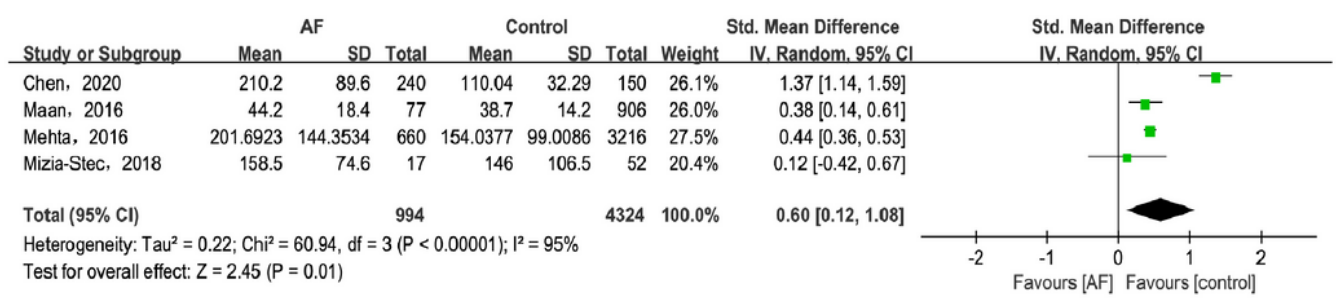

\section{B. Association between FGF-23 level and risk of AF}

\section{Highest vs lowest}

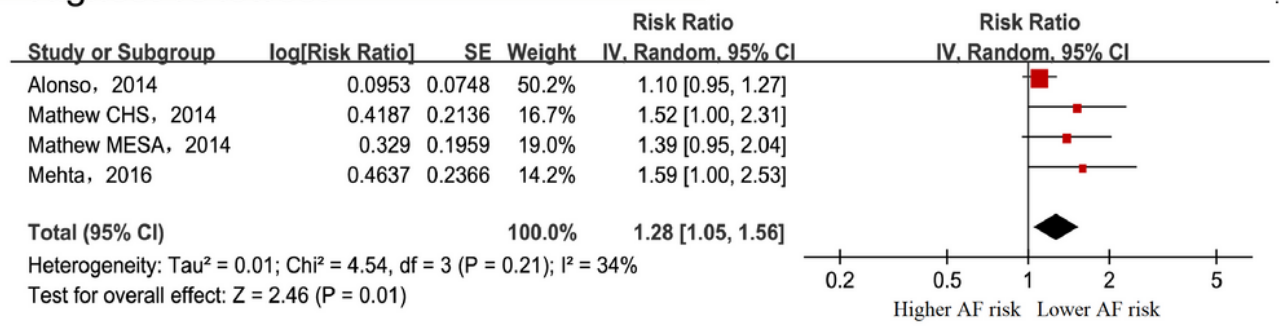

Dose-response analysis, per 20pg.ml increase

\begin{tabular}{|c|c|c|c|c|c|c|c|c|c|}
\hline Study or Subgroup & log[Risk Ratio] & SE & Weight & $\begin{array}{l}\text { Risk Ratio } \\
\text { IV. Random. } 95 \% \mathrm{Cl}\end{array}$ & & IV. F & sk $F$ & $\begin{array}{l}\text { Ratio } \\
\mathrm{m} .95 \% \mathrm{Cl}\end{array}$ & \\
\hline Alonso, 2014 & 0.04902589 & 0.03068496 & $74.2 \%$ & $1.05[0.99,1.12]$ & & & & & \\
\hline Mathew CHS, 2014 & 0.1181 & 0.055 & $23.1 \%$ & $1.13[1.01,1.25]$ & & & & & \\
\hline Mathew MESA, 2014 & 0.1951 & 0.159 & $2.8 \%$ & $1.22[0.89,1.66]$ & & & & & \\
\hline Total $(95 \% \mathrm{Cl})$ & & & $100.0 \%$ & $1.07[1.02,1.13]$ & & & & & \\
\hline \multicolumn{4}{|c|}{$\begin{array}{l}\text { Heterogeneity: } \mathrm{Tau}^{2}=0.00 ; \mathrm{Chi}^{2}=1.85, \mathrm{df}=2(\mathrm{P}=0.40) ; \mathrm{I}^{2}=0 \% \\
\text { Test for overall effect: } \mathrm{Z}=2.61(\mathrm{P}=0.009)\end{array}$} & & 0.5 & 0.7 & 1 & 1.5 & 2 \\
\hline
\end{tabular}

\section{Figure 3}

Forest plot showing the differences in serum fibroblast growth factor-23 level in control without AF and patients with AF (A) and the association between serum fibroblast growth factor-23 level and the risk of AF (B), upper panel: categorical analysis between fibroblast growth factor-23 level and the risk of AF; lower panel: dose-response association between fibroblast growth factor-23 level and the risk of AF, per $20 \mathrm{pg} / \mathrm{ml}$ increase. 


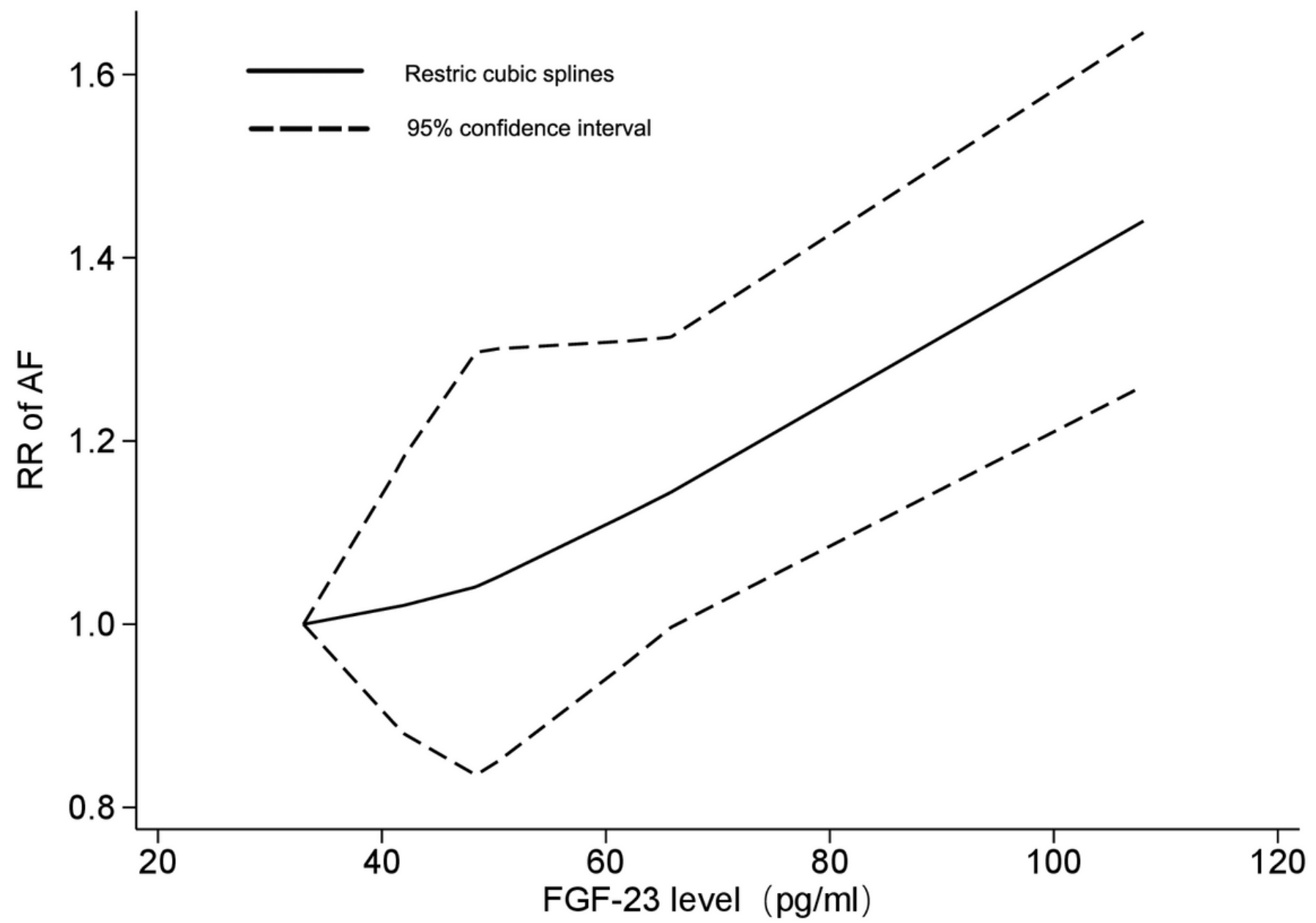

Figure 4

The dose-response association between the fibroblast growth factor-23 level and the risk of AF.

A non-linear exposure-effect analysis, the solid and dashed lines represent the estimated relative risk and the $95 \%$ confidence interval, respectively.

\section{Supplementary Files}

This is a list of supplementary files associated with this preprint. Click to download.

- supplementtable.docx 